\title{
Effectiveness and safety of direct oral anticoagulants compared to warfarin in treatment naïve non-valvular atrial fibrillation patients in the US Department of defense population
}

Kiran Gupta', Jeffrey Trocio², Allison Keshishian ${ }^{3 *}$ D , Qisu Zhang ${ }^{3}$, Oluwaseyi Dina², Jack Mardekian², Anagha Nadkarni ${ }^{1}$ and Thomas C Shank ${ }^{2}$

\begin{abstract}
Background: Clinical trials have demonstrated that direct oral anticoagulants (DOACs) are at least non-inferior to warfarin in reducing the risk of stroke/systemic embolism (SE) among patients with non-valvular atrial fibrillation (NVAF), but the comparative risk of major bleeding varies between DOACs and warfarin. Using US Department of Defense (DOD) data, this study compared the risk of stroke/SE and major bleeding for DOACs relative to warfarin.

Methods: Adult patients with $\geq 1$ pharmacy claim for apixaban, dabigatran, rivaroxaban, or warfarin from 01 Jan 2013-30 Sep 2015 were selected. Patients were required to have $\geq 1$ medical claim for atrial fibrillation during the 12-month baseline period. Patients with a warfarin or DOAC claim during the 12-month baseline period were excluded. Each DOAC cohort was matched to the warfarin cohort using propensity score matching (PSM). Cox proportional hazards models were conducted to evaluate the risk of stroke/SE and major bleeding of each DOAC vs warfarin.

Results: Of 41,001 identified patients, there were 3691 dabigatran-warfarin, 8226 rivaroxaban-warfarin, and 7607 apixaban-warfarin matched patient pairs. Apixaban was the only DOAC found to be associated with a significantly lower risk of stroke/SE (hazard ratio [HR]: 0.55; 95\% confidence interval [CI]: 0.39, 0.77; $p<0.001$ ) and major bleeding (HR: $0.65 ; 95 \%$ Cl: $0.53,0.80 ; p<0.001)$ compared to warfarin. Dabigatran and rivaroxaban initiation were associated with similar risk of stroke/SE (dabigatran: HR: $0.68 ; 95 \% \mathrm{Cl}: 0.43,1.07 ; p=0.096$; rivaroxaban: HR: $0.83 ; 95 \% \mathrm{Cl}$ : 0.64 , $1.09 ; p=0.187$ ) and major bleeding (dabigatran: HR: 1.05; $95 \% \mathrm{Cl}: 0.79,1.40 ; p=0.730$; rivaroxaban: HR: $1.07 ; 95 \%$ Cl: $0.91,1.27 ; p=0.423$ ) compared to warfarin.
\end{abstract}

Conclusion: Among NVAF patients in the US DOD population, apixaban was associated with significantly lower risk of stroke/SE and major bleeding compared to warfarin. Dabigatran and rivaroxaban were associated with similar risk of stroke/SE and major bleeding compared to warfarin.

Keywords: Non-valvular atrial fibrillation, Stroke/systemic embolism, Major bleeding, Warfarin, Direct oral anticoagulants

\footnotetext{
* Correspondence: akeshishian@statinmed.com

${ }^{3}$ STATinMED Research, 211 N 4th Ave, Ste 2B, Ann Arbor, MI 48104, USA

Full list of author information is available at the end of the article
}

(c) The Author(s). 2019 Open Access This article is distributed under the terms of the Creative Commons Attribution 4.0 International License (http://creativecommons.org/licenses/by/4.0/), which permits unrestricted use, distribution, and reproduction in any medium, provided you give appropriate credit to the original author(s) and the source, provide a link to the Creative Commons license, and indicate if changes were made. The Creative Commons Public Domain Dedication waiver (http://creativecommons.org/publicdomain/zero/1.0/) applies to the data made available in this article, unless otherwise stated. 


\section{Background}

Atrial fibrillation (AF) is an independent risk factor for stroke and increased mortality [1]. It was estimated that 5.2 million US adults were affected by AF in 2010, while in 2015 the prevalence of AF was close to 9.6 million. This number is projected to increase to 12.1 million by 2030, corresponding to a growth rate of $4.3 \%[2,3]$.

Warfarin, a vitamin K antagonist (VKA), has been the standard treatment for decades for stroke prevention among AF patients [4]. The American College of Cardiology/American Heart Association/ Heart Rhythm Society Guideline recommends oral anticoagulants (OACs) be used in patients with non-valvular AF (NVAF) and prior stroke, transient ischemic attack (TIA), or a $\mathrm{CHA}_{2} \mathrm{DS}_{2}$-VASc (congestive heart failure, hypertension, aged $>75$ years, diabetes, prior stroke or transient ischemic attack, thromboembolism, vascular disease, aged 65-74 years, and gender) score $\geq 2$ [5]. Besides warfarin, four direct oral anticoagulants (DOACs; dabigatran, rivaroxaban, apixaban, edoxaban) have received US Food and Drug Administration (FDA) approval. When compared with warfarin, DOACs have advantages of more predictable pharmacological profiles, fewer drug-drug interactions, an absence of major dietary effects, no requirement for regular international normalized ratio (INR) monitoring, and less risk of intracranial bleeding [5].

Four large prospective non-inferiority clinical trials have compared the effectiveness and safety between DOACs and warfarin among NVAF patients [6-9]. In the RE-LY trial, those prescribed $150 \mathrm{mg}$ dabigatran had lower rates of stroke/SE and similar rates of major bleeding compared to warfarin [6]. The ROCKET AF trial showed that patients prescribed rivaroxaban had non-inferior rates of stroke/SE and similar rates of major bleeding [7]. In the ARISTOTLE trial, apixaban demonstrated superiority to warfarin with lower rates of stroke/SE and major bleeding [8]. The ENGAGE AF trial showed that patients prescribed edoxaban had non-inferior rates of stroke/SE and lower rates of major bleeding compared to warfarin [9].

In addition to clinical trials, several real-world studies have evaluated comparative effectiveness and safety between DOACs and warfarin $[10,11]$. Being one of the largest health care plans in the US, the analysis of the US Department of Defense (DOD) health care system adds evidence and complements the profile in understanding the real-world treatment effects of OACs among NVAF patients in the US. However, few real-world studies using the DOD data have been conducted between DOACs and warfarin. The aim of this study was to compare the risk of stroke/SE and major bleeding between DOACs and warfarin in the DOD data.

\section{Methods}

\section{Data source}

This retrospective observational study used the US DOD data from January 1, 2012 to September 30, 2015. The DOD provides health care to over 9.4 million beneficiaries located in all 50 US states and multiple countries globally. Eligible beneficiaries include active duty, activated guard and reserve, retirees, survivors, some inactive guard and reserve, and their family members. Most beneficiaries are retired service members and their family members (5.42 million, 57\%), many of whom are Medicare eligible (3.18 million). Beneficiaries remain in the system for an average length of 7.2 years, which is $2-3$ times longer than commercial insurance plans. The data repository includes comprehensive datasets providing integrated information about the inpatient, outpatient, ER, and pharmacy claims from the US DOD facility and civilian/private sector care for eligible beneficiaries.

Medical and pharmacy claim coding utilizes the National Drug Code (NDC) coding system, Healthcare Common Procedure Coding System (HCPCS) codes, Current Procedural Terminology (CPT) codes, and the International Classification of Disease, 9th Revision, Clinical Modification (ICD-9-CM).

\section{Study population}

This study selected adult patients with $\geq 1$ pharmacy claim for an OAC (warfarin, apixaban, dabigatran, or rivaroxaban) from January 1, 2013 to September 30, 2015 (identification period). Edoxaban was not included in the analysis due to small sample size $(N=131)$. The first DOAC prescription claim date was defined as the index date for patients with a DOAC claim(s). For those without a DOAC claim, the first warfarin prescription claim date was defined as the index date. The baseline period was defined as one-year before the index date, during which patients had $\geq 1$ medical claim for AF (ICD-9-CM: 427.31) and continuous enrolment [12]. Patients were excluded from the study if they had claims for valvular heart disease, heart valve replacement, dialysis, kidney transplant, end-stage chronic kidney disease, venous thromboembolism, reversible AF, or a pharmacy claim for an OAC during the baseline period, hip or knee replacement within 6 weeks prior to the index date, $>1$ $\mathrm{OAC}$ claim on the index date, or a pregnancy diagnosis during the study period (Additional file 1: Table S1).

The follow-up period was defined as one day after the index date until the earliest of the following dates: OAC discontinuation date ( $\geq 30$-day gap between OAC prescriptions), switch to a non-index $\mathrm{OAC}<30$ days before or after discontinuation, death, end of continuous medical and pharmacy enrollment, or end of study period [13]. 


\section{Outcome measures}

Defined by primary or secondary diagnosis position on inpatient claims, stroke/SE was utilized as the effectiveness outcome measure while major bleeding served as the measure for safety outcomes. Stroke/SE was further classified into ischemic stroke, hemorrhagic stroke, and SE. Major bleeding consisted of intracranial hemorrhage (ICH), gastrointestinal (GI) bleeding, and major bleeding at other key sites. Validated administrative claim-based algorithms as well as published articles were used to derive the stroke/SE and major bleeding code lists. (Additional file 1: Table S2) [14-17].

\section{Baseline variables}

Baseline measurements included patient demographics, comorbidities, medications, hospitalizations during the 12-month baseline period, and clinical risk scores (HASBLED [hypertension, abnormal kidney or liver function, stroke, bleeding, age $>65$ years, and drugs/alcohol abuse or dependence], Charlson Comorbidity Index [CCI], and $\mathrm{CHA}_{2} \mathrm{DS}_{2}$-VASc).

The $\mathrm{CHA}_{2} \mathrm{DS}_{2}$-VASc stroke risk score and HAS-BLED bleeding risk scores were calculated (Additional file 1: Table S3 and Table S4) $[18,19]$. Note that for the HASBLED score, INR and other lab values were unavailable in the data; a modified score (range 0 to 8 ) was used.

\section{Statistical methods}

The design, analytical methods, and presentation of this study were informed by the guidelines for comparative effectiveness research $[20,21]$.

To assess significant differences for dichotomous variables, Pearson's Chi-square tests were performed. For continuous variables, student $\mathrm{t}$-tests were used.

To control for potential confounders between comparative cohorts (apixaban vs warfarin, rivaroxaban vs warfarin, and dabigatran vs warfarin), one-to-one propensity score matching (PSM) was used to balance demographics and clinical characteristics and to estimate the average treatment effects in patients with similar characteristics for whom each of the two OACs would be a reasonable treatment choice [22]. The logistic regression for the propensity score calculation included inpatient admissions, baseline medication use, age, gender, US geographic region, CCI score, HAS-BLED score, $\mathrm{CHA}_{2} \mathrm{DS}_{2}$-VASc score, stroke and bleeding history, and comorbidities [23]. The nearest neighbor method without replacement with a caliper of 0.01 was used. The balance of baseline patient characteristics was checked based on mean standardized differences with a threshold of $10 \%$ [24].

Incidence rates per 100 person-years of stroke/SE and major bleeding in PSM matched cohorts were calculated. To assess the risk of stroke/SE and major bleeding for patients in the matched cohorts, Cox proportional hazards models were utilized. Hazard ratios, 95\% confidence intervals (CIs), and $p$-values were provided. OAC treatment was included as the independent variable, and no other covariates were included in the model because the cohorts were balanced.

\section{Sensitivity analyses}

Sensitivity analyses, for the purpose of testing the robustness of the main results, were conducted. In the first of these analyses, cohorts were stratified by dosage of DOACs (standard and reduced) on the index date to assess if the outcomes were altered by DOACs dosage. The post-PSM population was separated per dosage of DOACs on the index date: standard-dose (apixaban 5 mg-warfarin, rivaroxaban $20 \mathrm{mg}$-warfarin, and dabigatran $150 \mathrm{mg}$-warfarin) and reduced-dose (apixaban 2.5 mg-warfarin, rivaroxaban $15 \mathrm{mg}$-warfarin, and dabigatran 75 mg-warfarin). In each matched subgroup by dosage of DOACs, imbalanced baseline variables with standardized difference $>10 \%$ were included in the Cox proportional hazards models. The statistical significance of the interaction term between treatment and dose was determined with a cutoff point of $p$-value $=0.10$.

Second, patients who had catheter ablation within 2 months prior to the index prescription and those who had cardioversion 1 month before or after index drug were excluded. After excluding those patients, the balance of the baseline characteristics was checked and variables which were unbalanced were incorporated in the multivariate model. These patients were excluded because they likely had a low risk of stroke and received the OACs for the procedures and not long-term stroke prevention. Third, a sensitivity analysis using the 6months after the index date as follow-up was also conducted. In this analysis, patients were censored at the earliest of: the OAC prescription discontinuation date, date of switching, date of death, date of disenrollment, end of the study period (September 30, 2015), or 6 months after the index date. This sensitivity analysis allowed the follow-up period to be more balanced between the cohorts. Lastly, a sensitivity analysis using the intent-to-treat method was used, where patients were followed based on the index drug regardless of discontinuation or switch.

\section{Results}

\section{Baseline characteristics}

After applying the selection criteria and before performing the PSM, a total of 41,001 patients were included in the study, including 9255 (22.6\%) warfarin, 4312 (10.5\%) dabigatran, 15,680 (38.2\%) rivaroxaban, and $11,754(28.7 \%)$ apixaban patients. Warfarin initiators were older with significantly higher baseline mean 
$\mathrm{CCI}$ and $\mathrm{CHA}_{2} \mathrm{DS}_{2}$-VASc scores vs those who initiated apixaban, rivaroxaban, and dabigatran. After 1:1 PSM, there were 3691 dabigatran-warfarin matched pairs, 8226 rivaroxaban-warfarin matched pairs, and 7607 apixaban-warfarin matched pairs (Fig. 1).

After PSM, baseline demographic and clinical characteristics were balanced between the matched cohorts with standardized difference less than 10\%. Dabigatranwarfarin patients had the best health status with a mean CCI score of 2.0, $\mathrm{CHA}_{2} \mathrm{DS}_{2}$-VASc score of 3.7, and HAS-BLED score of 2.8, followed by rivaroxabanwarfarin and apixaban-warfarin patients with a mean CCI score approximately 2.5, $\mathrm{CHA}_{2} \mathrm{DS}_{2}$-VASc score around 4.1, and HAS-BLED score of 3.0 (Table 1).

\section{Effectiveness outcomes}

The incidence rates of stroke/SE are shown in Fig. 2. Apixaban (hazard ratio [HR]: 0.55; 95\% CI: 0.39, 0.77; $p<0.001)$ was associated with a significantly lower risk of stroke/SE compared to warfarin. Apixaban was also associated with a significantly lower risk of hemorrhagic stroke (HR: $0.49 ; 95 \%$ CI: $0.25,0.93 ; p=0.030$ ) and SE (HR: 0.07; 95\% CI: 0.01, 0.54; $p=0.010$ ).

Compared to warfarin, dabigatran (HR: 0.68 ; $95 \% \mathrm{CI}$ : $0.43,1.07 ; p=0.096$ ) and rivaroxaban (HR: 0.83 ; 95\% CI: $0.64,1.09 ; p=0.187)$ were associated with a nonsignificantly lower risk of stroke/SE (Fig. 2). Both dabigatran (HR: 0.24; 95\% CI: 0.07, 0.88; $p=0.031$ ) and rivaroxaban (HR: $0.57 ; 95 \%$ CI: $0.34,0.95 ; p=0.032$ ) had a lower risk of hemorrhagic stroke versus warfarin.

\section{Safety outcomes}

The incidence rates of major bleeding are shown in Fig. 3. Apixaban (HR: 0.65; 95\% CI: $0.53,0.80 ; p<$ 0.001 ) patients had a significantly lower risk of major bleeding compared to warfarin. The decrease in major bleeding risk was driven by all types of major bleeding, including GI, ICH, and other major bleeding. Dabiga$\operatorname{tran}(\mathrm{HR}: 1.05$; 95\% CI: 0.79, 1.40; $p=0.730$ ) and rivaroxaban (HR: $1.07 ; 95 \%$ CI: $0.91,1.27 ; p=0.423$ ) were associated with similar risks of major bleeding compared to warfarin (Fig. 3). Both dabigatran (HR: 0.30; 95\% CI: $0.13,0.71 ; p=0.006$ ) and rivaroxaban (HR: 0.56; 95\% CI: 0.37, 0.84; $p=0.005$ ) were associated with a significantly lower risk of $\mathrm{ICH}$ versus warfarin; however, rivaroxaban was associated with a significantly higher risk of GI bleeding (HR: 1.30; 95\% CI: 1.06,1.60; $p=0.013)$.

\section{Sensitivity analyses}

The results were generally consistent in the dose subgroup analysis compared to the results in the main analysis (Table 2). There was a significant interaction for rivaroxaban treatment dose and major bleeding. The second and third sensitivity analyses showed results similar to the results of the main analysis. In the

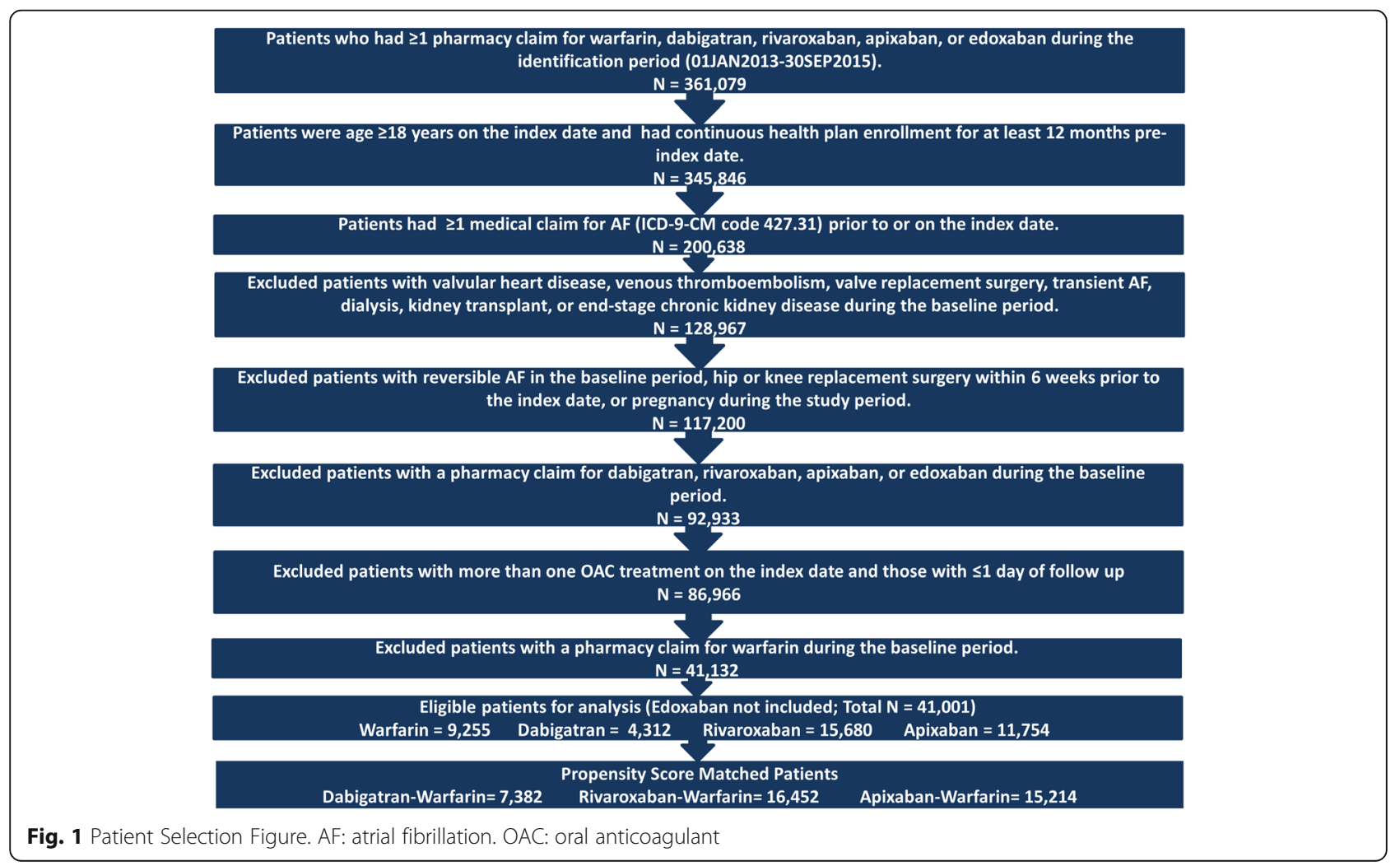


Table 1 Demographic and Clinical Characteristics in Propensity Score Matched DOAC and Warfarin Cohorts

\begin{tabular}{|c|c|c|c|c|c|c|c|c|c|c|c|c|}
\hline & \multicolumn{2}{|c|}{$\begin{array}{l}\text { Warfarin Cohort } \\
(N=3691)\end{array}$} & \multicolumn{2}{|c|}{$\begin{array}{l}\text { Dabigatran Cohort } \\
(N=3691)\end{array}$} & \multicolumn{2}{|c|}{$\begin{array}{l}\text { Warfarin Cohort } \\
(N=8226)\end{array}$} & \multicolumn{2}{|c|}{$\begin{array}{l}\text { Rivaroxaban Cohort } \\
(N=8226)\end{array}$} & \multicolumn{2}{|c|}{$\begin{array}{l}\text { Warfarin Cohort } \\
(N=7607)\end{array}$} & \multicolumn{2}{|c|}{$\begin{array}{l}\text { Apixaban Cohort } \\
(N=7607)\end{array}$} \\
\hline & N/Mean & $\% / S D$ & N/Mean & $\% / S D$ & N/Mean & $\% / S D$ & N/Mean & $\% / S D$ & N/Mean & $\% / S D$ & N/Mean & $\% / S D$ \\
\hline Age & 74.0 & 10.3 & 74.0 & 9.5 & 76.5 & 9.7 & 76.5 & 9.3 & 76.6 & 9.8 & 76.5 & 9.5 \\
\hline $18-54$ & 134 & $3.6 \%$ & 106 & $2.9 \%$ & 180 & $2.2 \%$ & 168 & $2.0 \%$ & 178 & $2.3 \%$ & 172 & $2.3 \%$ \\
\hline $55-64$ & 425 & $11.5 \%$ & 434 & $11.8 \%$ & 625 & $7.6 \%$ & 590 & $7.2 \%$ & 563 & $7.4 \%$ & 558 & $7.3 \%$ \\
\hline $65-74$ & 1244 & $33.7 \%$ & 1286 & $34.8 \%$ & 2278 & $27.7 \%$ & 2275 & $27.7 \%$ & 2057 & $27.0 \%$ & 2157 & $28.4 \%$ \\
\hline$\geq 75$ & 1888 & $51.2 \%$ & 1865 & $50.5 \%$ & 5143 & $62.5 \%$ & 5193 & $63.1 \%$ & 4809 & $63.2 \%$ & 4720 & $62.0 \%$ \\
\hline \multicolumn{13}{|l|}{ Gender } \\
\hline Male & 2240 & $60.7 \%$ & 2245 & $60.8 \%$ & 4812 & $58.5 \%$ & 4791 & $58.2 \%$ & 4430 & $58.2 \%$ & 4431 & $58.2 \%$ \\
\hline Female & 1451 & $39.3 \%$ & 1446 & $39.2 \%$ & 3414 & $41.5 \%$ & 3435 & $41.8 \%$ & 3177 & $41.8 \%$ & 3176 & $41.8 \%$ \\
\hline \multicolumn{13}{|l|}{ Geographic Region } \\
\hline Northeast & 270 & $7.3 \%$ & 282 & $7.6 \%$ & 807 & $9.8 \%$ & 788 & $9.6 \%$ & 644 & $8.5 \%$ & 632 & $8.3 \%$ \\
\hline North Central & 559 & $15.1 \%$ & 566 & $15.3 \%$ & 1409 & $17.1 \%$ & 1377 & $16.7 \%$ & 1191 & $15.7 \%$ & 1182 & $15.5 \%$ \\
\hline South & 1862 & $50.4 \%$ & 1865 & $50.5 \%$ & 3701 & $45.0 \%$ & 3709 & $45.1 \%$ & 3688 & $48.5 \%$ & 3672 & $48.3 \%$ \\
\hline West & 929 & $25.2 \%$ & 911 & $24.7 \%$ & 2138 & $26.0 \%$ & 2174 & $26.4 \%$ & 1933 & $25.4 \%$ & 1966 & $25.8 \%$ \\
\hline Other & 71 & $1.9 \%$ & 67 & $1.8 \%$ & 171 & $2.1 \%$ & 178 & $2.2 \%$ & 151 & $2.0 \%$ & 155 & $2.0 \%$ \\
\hline \multicolumn{13}{|l|}{ Baseline Comorbidity } \\
\hline Deyo-Charlson Comorbidity Index & 2.0 & 2.1 & 2.0 & 2.1 & 2.5 & 2.4 & 2.5 & 2.4 & 2.5 & 2.4 & 2.5 & 2.4 \\
\hline CHADS2 Score & 2.3 & 1.3 & 2.3 & 1.4 & 2.5 & 1.4 & 2.6 & 1.4 & 2.6 & 1.4 & 2.6 & 1.4 \\
\hline $0=$ low risk & 309 & $8.4 \%$ & 298 & $8.1 \%$ & 453 & $5.5 \%$ & 491 & $6.0 \%$ & 408 & $5.4 \%$ & 422 & $5.5 \%$ \\
\hline $1=$ moderate risk & 782 & $21.2 \%$ & 835 & $22.6 \%$ & 1408 & $17.1 \%$ & 1459 & $17.7 \%$ & 1294 & $17.0 \%$ & 1318 & $17.3 \%$ \\
\hline $2=$ high risk & 1209 & $32.8 \%$ & 1166 & $31.6 \%$ & 2528 & $30.7 \%$ & 2351 & $28.6 \%$ & 2360 & $31.0 \%$ & 2247 & $29.5 \%$ \\
\hline$>2=$ high risk & 1391 & $37.7 \%$ & 1392 & $37.7 \%$ & 3837 & $46.6 \%$ & 3925 & $47.7 \%$ & 3545 & $46.6 \%$ & 3620 & $47.6 \%$ \\
\hline CHADS2-VASc Score & 3.7 & 1.8 & 3.7 & 1.8 & 4.1 & 1.7 & 4.1 & 1.8 & 4.1 & 1.8 & 4.2 & 1.8 \\
\hline $0=$ low risk & 84 & $2.3 \%$ & 99 & $2.7 \%$ & 117 & $1.4 \%$ & 117 & $1.4 \%$ & 111 & $1.5 \%$ & 108 & $1.4 \%$ \\
\hline $1=$ moderate risk & 303 & $8.2 \%$ & 251 & $6.8 \%$ & 414 & $5.0 \%$ & 389 & $4.7 \%$ & 377 & $5.0 \%$ & 363 & $4.8 \%$ \\
\hline $2=$ high risk & 517 & $14.0 \%$ & 562 & $15.2 \%$ & 901 & $11.0 \%$ & 931 & $11.3 \%$ & 832 & $10.9 \%$ & 872 & $11.5 \%$ \\
\hline$>2=$ high risk & 2787 & $75.5 \%$ & 2779 & $75.3 \%$ & 6794 & $82.6 \%$ & 6789 & $82.5 \%$ & 6287 & $82.6 \%$ & 6264 & $82.3 \%$ \\
\hline HAS-BLED Score & 2.8 & 1.3 & 2.8 & 1.2 & 3.0 & 1.3 & 3.0 & 1.3 & 3.0 & 1.3 & 3.0 & 1.3 \\
\hline $0=$ low risk & 92 & $2.49 \%$ & 80 & $2.17 \%$ & 117 & $1.42 \%$ & 101 & $1.23 \%$ & 110 & $1.45 \%$ & 100 & $1.31 \%$ \\
\hline $1-2=$ moderate risk & 1544 & $41.8 \%$ & 1472 & $39.9 \%$ & 3007 & $36.6 \%$ & 2982 & $36.3 \%$ & 2737 & $36.0 \%$ & 2606 & $34.3 \%$ \\
\hline$>2=$ high risk & 2055 & $55.7 \%$ & 2139 & $58.0 \%$ & 5102 & $62.0 \%$ & 5143 & $62.5 \%$ & 4760 & $62.6 \%$ & 4901 & $64.4 \%$ \\
\hline Baseline Prior Bleed & 573 & $15.5 \%$ & 572 & $15.5 \%$ & 1611 & $19.6 \%$ & 1632 & $19.8 \%$ & 1484 & $19.5 \%$ & 1525 & $20.0 \%$ \\
\hline Baseline Prior Stroke & 354 & $9.6 \%$ & 341 & $9.2 \%$ & 1034 & $12.6 \%$ & 1028 & $12.5 \%$ & 907 & $11.9 \%$ & 931 & $12.2 \%$ \\
\hline Congestive Heart Failure & 749 & $20.3 \%$ & 752 & $20.4 \%$ & 2184 & $26.5 \%$ & 2207 & $26.8 \%$ & 2033 & $26.7 \%$ & 2052 & $27.0 \%$ \\
\hline Diabetes & 1211 & $32.8 \%$ & 1220 & $33.1 \%$ & 2853 & $34.7 \%$ & 2815 & $34.2 \%$ & 2593 & $34.1 \%$ & 2631 & $34.6 \%$ \\
\hline Hypertension & 3055 & $82.8 \%$ & 3059 & $82.9 \%$ & 6903 & $83.9 \%$ & 6881 & $83.6 \%$ & 6450 & $84.8 \%$ & 6469 & $85.0 \%$ \\
\hline Renal Disease & 625 & $16.9 \%$ & 640 & $17.3 \%$ & 1918 & $23.3 \%$ & 1943 & $23.6 \%$ & 1839 & $24.2 \%$ & 1852 & $24.3 \%$ \\
\hline Myocardial Infarction & 202 & $5.5 \%$ & 204 & $5.5 \%$ & 513 & $6.2 \%$ & 525 & $6.4 \%$ & 479 & $6.3 \%$ & 485 & $6.4 \%$ \\
\hline Dyspepsia or Stomach Discomfort & 645 & $17.5 \%$ & 652 & $17.7 \%$ & 1500 & $18.2 \%$ & 1492 & $18.1 \%$ & 1398 & $18.4 \%$ & 1404 & $18.5 \%$ \\
\hline Peripheral Vascular Disease & 1607 & $43.5 \%$ & 1615 & $43.8 \%$ & 4005 & $48.7 \%$ & 3986 & $48.5 \%$ & 3742 & $49.2 \%$ & 3755 & $49.4 \%$ \\
\hline Transient Ischemic Attack & 255 & $6.9 \%$ & 236 & $6.4 \%$ & 647 & $7.9 \%$ & 663 & $8.1 \%$ & 596 & $7.8 \%$ & 599 & $7.9 \%$ \\
\hline Coronary Artery Disease & 1347 & $36.5 \%$ & 1361 & $36.9 \%$ & 3331 & $40.5 \%$ & 3311 & $40.3 \%$ & 3126 & $41.1 \%$ & 3146 & $41.4 \%$ \\
\hline
\end{tabular}


Table 1 Demographic and Clinical Characteristics in Propensity Score Matched DOAC and Warfarin Cohorts (Continued)

\begin{tabular}{|c|c|c|c|c|c|c|c|c|c|c|c|c|}
\hline & \multicolumn{2}{|c|}{$\begin{array}{l}\text { Warfarin Cohort } \\
(N=3691)\end{array}$} & \multicolumn{2}{|c|}{$\begin{array}{l}\text { Dabigatran Cohort } \\
(N=3691)\end{array}$} & \multicolumn{2}{|c|}{$\begin{array}{l}\text { Warfarin Cohort } \\
(N=8226)\end{array}$} & \multicolumn{2}{|c|}{$\begin{array}{l}\text { Rivaroxaban Cohort } \\
(N=8226)\end{array}$} & \multicolumn{2}{|c|}{$\begin{array}{l}\text { Warfarin Cohort } \\
(N=7607)\end{array}$} & \multicolumn{2}{|c|}{$\begin{array}{l}\text { Apixaban Cohort } \\
(N=7607)\end{array}$} \\
\hline & N/Mean & $\% / S D$ & N/Mean & $\% / S D$ & N/Mean & $\% / S D$ & N/Mean & $\% / S D$ & N/Mean & $\% / S D$ & N/Mean & $\% / S D$ \\
\hline $\begin{array}{l}\text { Angiotensin Converting Enzyme } \\
\text { Inhibitor }\end{array}$ & 1285 & $34.8 \%$ & 1264 & $34.2 \%$ & 2938 & $35.7 \%$ & 2950 & $35.9 \%$ & 2714 & $35.7 \%$ & 2696 & $35.4 \%$ \\
\hline Amiodarone & 340 & $9.2 \%$ & 336 & $9.1 \%$ & 814 & $9.9 \%$ & 843 & $10.2 \%$ & 765 & $10.1 \%$ & 772 & $10.1 \%$ \\
\hline Angiotensin Receptor Blocker & 930 & $25.2 \%$ & 958 & $26.0 \%$ & 1993 & $24.2 \%$ & 1990 & $24.2 \%$ & 1921 & $25.3 \%$ & 1983 & $26.1 \%$ \\
\hline Beta Blockers & 2509 & $68.0 \%$ & 2540 & $68.8 \%$ & 5659 & $68.8 \%$ & 5702 & $69.3 \%$ & 5304 & $69.7 \%$ & 5286 & $69.5 \%$ \\
\hline H2-receptor Antagonist & 203 & $5.5 \%$ & 228 & $6.2 \%$ & 597 & $7.3 \%$ & 597 & $7.3 \%$ & 521 & $6.8 \%$ & 521 & $6.8 \%$ \\
\hline Proton Pump Inhibitor & 1324 & $35.9 \%$ & 1345 & $36.4 \%$ & 2972 & $36.1 \%$ & 2964 & $36.0 \%$ & 2817 & $37.0 \%$ & 2813 & $37.0 \%$ \\
\hline Anti-platelets & 836 & $22.6 \%$ & 818 & $22.2 \%$ & 1718 & $20.9 \%$ & 1705 & $20.7 \%$ & 1668 & $21.9 \%$ & 1740 & $22.9 \%$ \\
\hline Statins & 2188 & $59.3 \%$ & 2182 & $59.1 \%$ & 4897 & $59.5 \%$ & 4903 & $59.6 \%$ & 4572 & $60.1 \%$ & 4616 & $60.7 \%$ \\
\hline Dronedarone & 106 & $2.9 \%$ & 112 & $3.0 \%$ & 157 & $1.9 \%$ & 182 & $2.2 \%$ & 151 & $2.0 \%$ & 140 & $1.8 \%$ \\
\hline Calcium Channel Blockers & 1432 & $38.8 \%$ & 1457 & $39.5 \%$ & 3189 & $38.8 \%$ & 3156 & $38.4 \%$ & 3001 & $39.5 \%$ & 3000 & $39.4 \%$ \\
\hline Baseline Hospitalization & 1387 & $37.6 \%$ & 1368 & $37.1 \%$ & 3559 & $43.3 \%$ & 3612 & $43.9 \%$ & 3217 & $42.3 \%$ & 3237 & $42.6 \%$ \\
\hline \multicolumn{13}{|l|}{ Dosage on Index Date } \\
\hline Standard & & & 3125 & $84.7 \%$ & & & 5665 & $68.9 \%$ & & & 5714 & $75.1 \%$ \\
\hline \multicolumn{13}{|l|}{ Follow-up Time (in days) } \\
\hline minimum & 1 & & 1 & & 1 & & 1 & & 1 & & 1 & \\
\hline Q1 & 56 & & 63 & & 57 & & 61 & & 57 & & 64 & \\
\hline median & 148 & & 163 & & 150 & & 177 & & 153 & & 161 & \\
\hline Q3 & 358 & & 436 & & 354 & & 411 & & 359 & & 333 & \\
\hline maximum & 1001 & & 999 & & 1001 & & 1002 & & 1001 & & 951 & \\
\hline
\end{tabular}

SD Standard deviation, SE Systemic embolism, $\mathrm{CHADS}_{2}$ Congestive heart failure, hypertension, age $\geq 75$ years, diabetes mellitus, prior stroke or transient ischemic attack or thromboembolism; $C H A_{2} D S_{2} V A S_{C}$ Congestive heart failure, hypertension, age $\geq 75$ years, diabetes mellitus, prior stroke or transient ischemic attack or thromboembolism, vascular disease, age 65-74 years, gender category; HAS-BLED Hypertension, abnormal renal and liver function, stroke, bleeding, labile INRs (international normalized ratio), elderly, drugs and alcohol, ACE Angiotensin-converting enzyme inhibitor, ARB Angiotensin-receptor blocker, NSAIDs Non-steroidal anti-inflammatory drugs

sensitivity analysis where patients with cardioversion and catheter ablation (i.e., low risk stroke patients) were excluded, patients who initiated rivaroxaban had a significantly lower risk of stroke/SE compared to patients who initiated warfarin (Table 3). All other trends remained the same.

\section{Discussion}

In this real-world study among NVAF patients initiating OAC treatment in the US DOD population, apixaban was found to be the only DOAC associated with a significantly lower risk of stroke/SE and major bleeding compared to warfarin, while dabigatran and rivaroxaban initiation were associated with similar risk of stroke/SE and major bleeding compared to warfarin. These findings were supported by several sensitivity analyses.

This observational study adds real-world evidence to supplement the results from clinical trials. In the RE-LY trial, compared to warfarin, $110 \mathrm{mg}$ dabigatran (not approved in the US) was associated with similar risk of stroke/SE and lower risk of major bleeding, while 150 mg dabigatran had a significantly lower risk of stroke/SE and similar risk of major bleeding [6]. However, in our study, we observed a similar risk of stroke/SE and major bleeding among dabigatran patients compared to warfarin patients. In the ROCKET-AF clinical trial, rivaroxaban was non-inferior for both stroke/SE and major bleeding compared to warfarin [7]. Similarly, our study showed a consistent safety result but numerically lower effectiveness results comparing rivaroxaban and warfarin. Consistent with our study, the ARISTOTLE trial found apixaban showed superiority to warfarin in terms of the risk of stroke/SE and major bleeding [8].

In addition to clinical trials, a few real-world studies have also examined the risk of stroke and major bleeding of OACs. In prior effectiveness and safety comparisons between dabigatran and warfarin, dabigatran was shown to have similar to lower risk of stroke/SE and major bleeding versus warfarin. In the Villines et al. study, which also used US DOD data, dabigatran was shown to be associated with a lower risk of stroke and similar risk of major bleeding compared to warfarin [25]. Consistent 


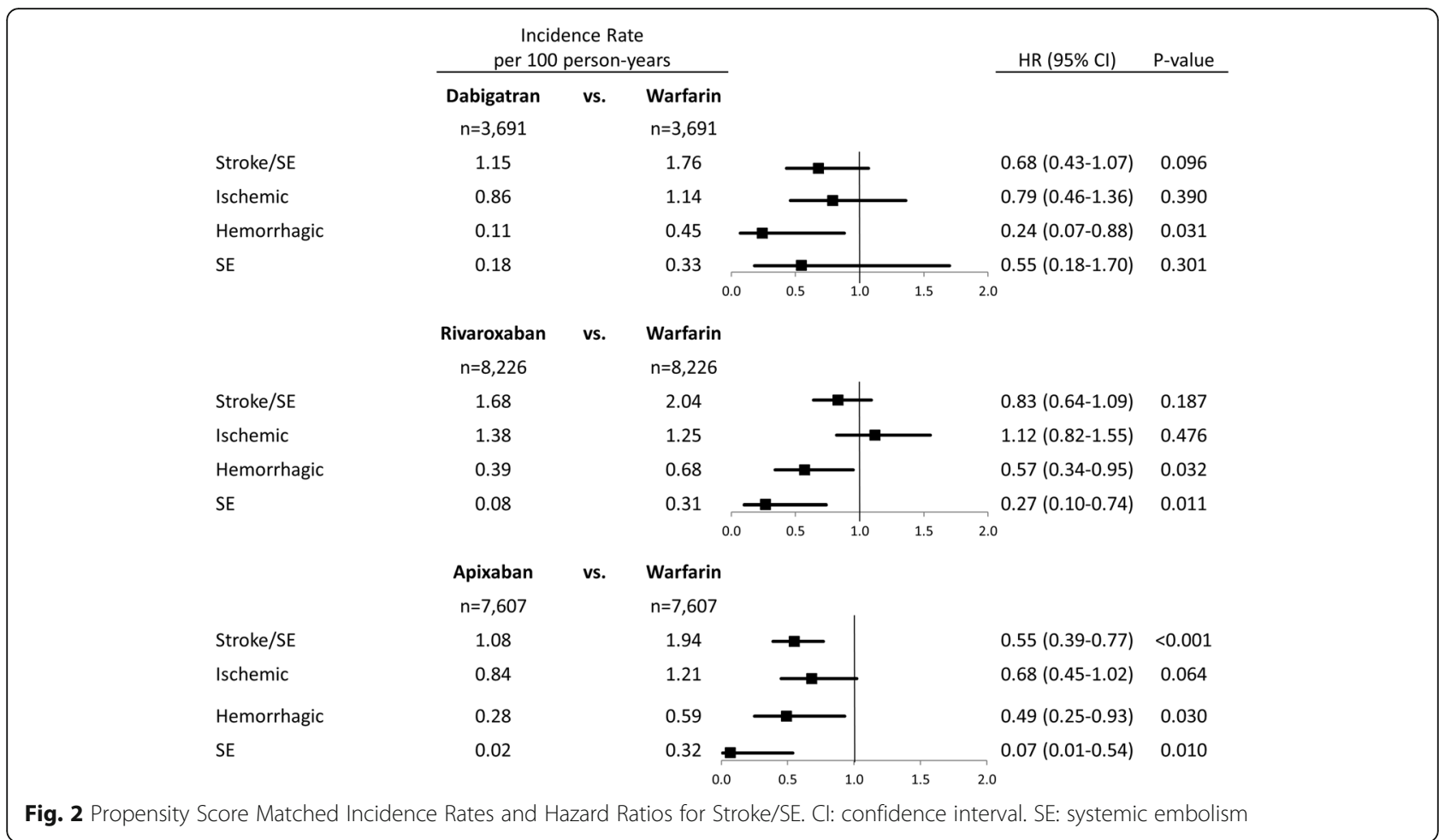

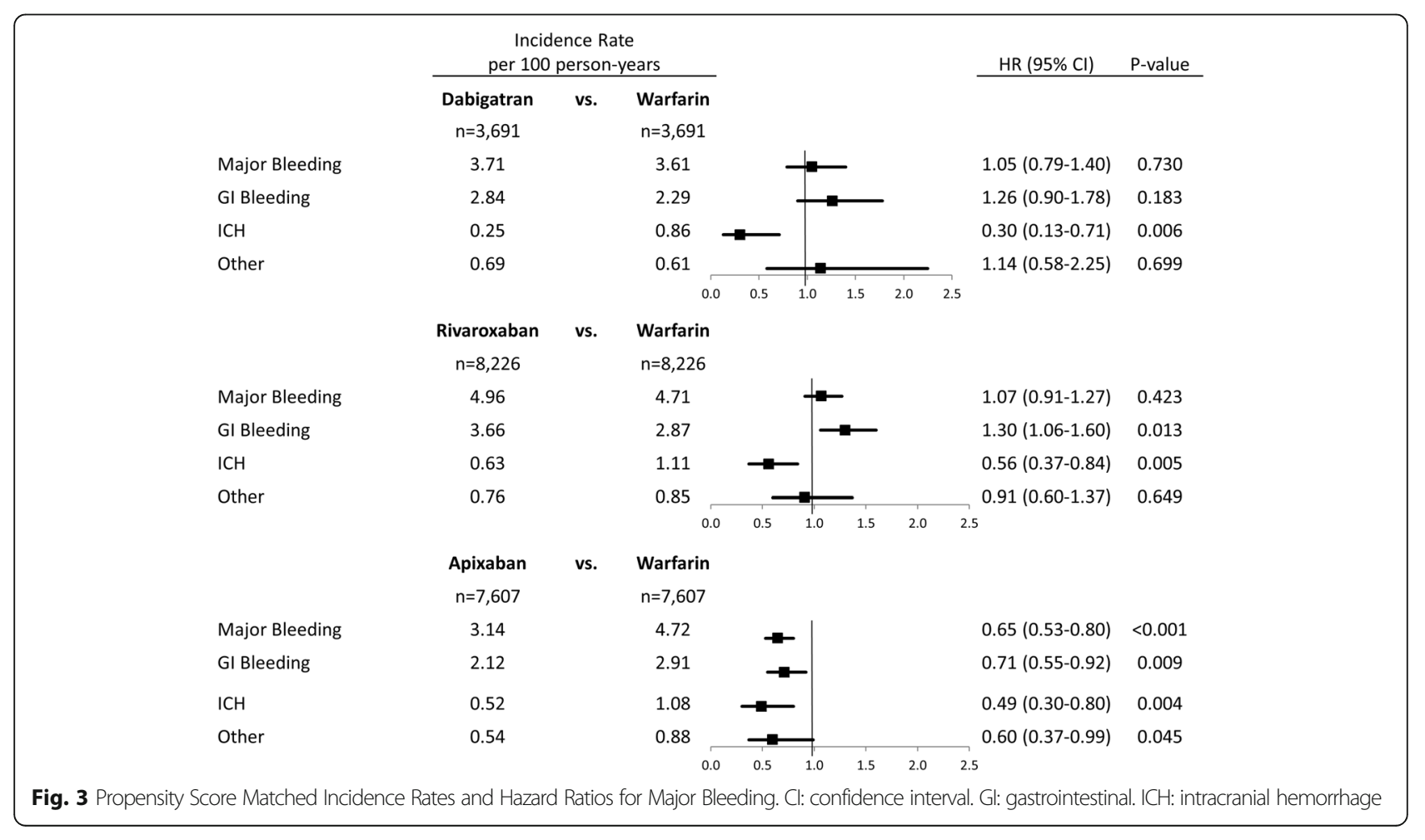


Table 2 Dose Sensitivity Analysis for Propensity Score Matched Patients

\begin{tabular}{|c|c|c|c|c|c|c|c|c|c|}
\hline & \multicolumn{2}{|c|}{ Dabigatran vs Warfarin } & $P$ value* & \multicolumn{2}{|c|}{ Rivaroxaban vs Warfarin } & $P$ value* & \multicolumn{2}{|c|}{ Apixaban vs Warfarin } & $P$ value $^{*}$ \\
\hline \multicolumn{10}{|l|}{ Stroke/SE } \\
\hline Reduced Dose & $\begin{array}{l}N=566 \mathrm{vs} \\
N=566\end{array}$ & $0.72(0.25,2.04)$ & 0.857 & $\begin{array}{l}N=2561 \mathrm{vs} \\
N=2561\end{array}$ & $0.77(0.49,1.20)$ & 0.694 & $\begin{array}{l}N=1893 \text { vs } \\
N=1893\end{array}$ & $0.72(0.38,1.39)$ & 0.315 \\
\hline Standard Dose & $\begin{array}{l}N=3125 \mathrm{vs} \\
N=3125\end{array}$ & $0.64(0.39,1.07)$ & & $\begin{array}{l}N=5665 \mathrm{vs} \\
N=5665\end{array}$ & $0.86(0.61,1.22)$ & & $\begin{array}{l}N=5714 \mathrm{vs} \\
N=5714\end{array}$ & $0.49(0.32,0.73)$ & \\
\hline \multicolumn{10}{|l|}{ Major bleeding } \\
\hline Reduced Dose & $\begin{array}{l}N=566 \mathrm{vs} \\
N=566\end{array}$ & $1.30(0.70,2.41)$ & 0.369 & $\begin{array}{l}N=2561 \mathrm{vs} \\
N=2561\end{array}$ & $0.84(0.63,1.12)$ & 0.054 & $\begin{array}{l}N=1893 v s \\
N=1893\end{array}$ & $0.66(0.46,0.95)$ & 0.803 \\
\hline Standard Dose & $\begin{array}{l}N=3125 \text { vs } \\
N=3125\end{array}$ & $0.94(0.68,1.31)$ & & $\begin{array}{l}N=5665 \mathrm{vs} \\
N=5665\end{array}$ & $1.19(0.97,1.47)$ & & $\begin{array}{l}N=5714 \mathrm{vs} \\
N=5714\end{array}$ & $0.62(0.48,0.81)$ & \\
\hline
\end{tabular}

* $P$-value is for interaction. $\mathrm{Cl}$ Confidence interval, $H R$ Hazard ratio

with the Villines et al. study, in a study using Medicare data, dabigatran was associated with a lower risk of ischemic stroke and similar risk of major bleeding compared to warfarin [11]. In a meta-analysis including 20 observational studies comparing dabigatran and warfarin, dabigatran was found to have a lower risk of ischemic stroke and major bleeding [26]. However, another meta-analysis found no statistical difference between dabigatran and VKA for ischemic stroke or major bleeding [10] Dabigatran $110 \mathrm{mg}$ is not available in the US; therefore, this study included patients prescribed $150 \mathrm{mg}$ or $75 \mathrm{mg}$ dabigatran and may not be generalizable to countries where $110 \mathrm{mg}$ dabigatran is available. Our study indicated that dabigatran had a numerically lower risk of stroke/SE and similar risk of major bleeding compared to warfarin. Since the dabigatran cohort has the smallest sample size in our study, a larger sample size may be warranted for this population to examine the difference between dabigatran and warfarin.

In many real-world comparisons of rivaroxaban and warfarin, rivaroxaban was associated with a similar risk of stroke/SE and major bleeding compared to warfarin; however, some inconsistencies exist in other real-world studies. In a meta-analysis of observational study, Ntaios et al. found that there was no statistical difference between rivaroxaban and VKA for stroke/ SE and major hemorrhage [10]. However, in a metaanalysis, Bai et al. found that rivaroxaban was associated with a lower risk of stroke/SE and a similar risk of major bleeding [27]. In Amin et al. (Medicare data), rivaroxaban was associated with a lower risk of stroke/SE, but a higher risk of major bleeding compared to warfarin [17]. Tamayo et al. evaluated major bleeding incidence rates among rivaroxaban users in the DOD population and found the incidence of major bleeding to be 2.86 per 100 person-years. The reported incidence is smaller than our study where the incidence of major bleeding was 4.96 per 100 person-years. The difference may have been due to different selection criteria; for example, we excluded patients with previous anticoagulant use, and we used a different definition of major bleeding [28].

In this study, apixaban was the only DOAC that showed significant safety and effectiveness results,

Table 3 Other Sensitivity Analyses for Propensity Score Matched Patients

\begin{tabular}{|c|c|c|c|}
\hline & Dabigatran vs Warfarin & Rivaroxaban vs Warfarin & Apixaban vs Warfarin \\
\hline \multicolumn{4}{|c|}{ Censoring at 6 Months, HR (95\% Cl) } \\
\hline Sample Size & $N=3691$ vs $N=3691$ & $N=8226$ vs $N=8226$ & $N=7607$ vs $N=7607$ \\
\hline Stroke/SE & $0.68(0.37-1.23)$ & $0.90(0.63-1.29)$ & $0.51(0.33-0.79)$ \\
\hline Major bleeding & $1.10(0.75-1.61)$ & $1.12(0.91-1.39)$ & $0.59(0.45-0.77)$ \\
\hline \multicolumn{4}{|c|}{ Intent-to-Treat, HR (95\% Cl) } \\
\hline Sample Size & $N=3691$ vs $N=3691$ & $N=8226$ vs $N=8226$ & $N=7607$ vs $N=7607$ \\
\hline Stroke/SE & $0.76(0.57-1.03)$ & $1.04(0.86-1.26)$ & $0.63(0.49-0.81)$ \\
\hline Major bleeding & $0.97(0.80-1.19)$ & $1.01(0.89-1.15)$ & $0.75(0.64-0.88)$ \\
\hline \multicolumn{4}{|c|}{ Excluding Patients with Catheter Ablation or Cardioversion, HR (95\% Cl) } \\
\hline Sample Size & $N=3298$ vs $N=3298$ & $N=7698$ vs $N=7698$ & $N=7034$ vs $N=7034$ \\
\hline Stroke/SE & $0.68(0.43-1.07)$ & $0.83(0.64-1.09)$ & $0.55(0.39-0.77)$ \\
\hline Major bleeding & $1.05(0.79-1.40)$ & $1.07(0.91-1.27)$ & $0.65(0.53-0.80)$ \\
\hline
\end{tabular}

CI Confidence interval, HR Hazard ratio, SE Systemic embolism 
which is generally consistent with other real-world studies. Similarly, in a study pooling four claims datasets, apixaban initiators were associated with a $33 \%$ lower risk of stroke/SE and 40\% lower risk of major bleeding compared with warfarin initiators [29]. In the Amin et al. study using Medicare data, apixaban was also associated with both significantly lower risk of stroke/SE and major bleeding compared to warfarin [17]. The Ntaios et al. meta-analysis demonstrated that apixaban was associated with a similar risk of ischemic stroke/SE and lower risk of major hemorrhage compared to warfarin [10]. Another meta-analysis of apixaban and warfarin comparisons showed that apixaban had similar risk of stroke/SE and lower risk of major bleeding versus warfarin [30].

By comparing the effectiveness and safety of DOACs versus warfarin using the most recent DOD data, this study provides supplemental information for the clinical trials as well as the real-world study profiles. To our knowledge, this was the first study using DOD data to examine the effectiveness and safety of all DOACs compared to warfarin. Findings from this study may inform decision makers and health care providers in the DOD and other health care systems.

This study has several limitations. First, due to the nature of claims studies, diagnoses and procedures in this study were identified using ICD-9-CM, CPT, HCPCS, and NDC codes. These coding systems were originally designed for billing purposes rather than research, without further adjudication using precise clinical criteria. Second, although cohorts were PSM, potential residual confounders exist hence no causal inferences can be drawn. In addition, since PSM was conducted between each DOAC and warfarin, no comparisons across the three DOACs should be made. Although no direct comparison to the clinical trials can be made given the nature of observational study, our findings from the main, subgroup, and sensitivity analyses provided additional real-world evidence and support for the clinical trial study results. Finally, only treatment-naïve patients and the DOD population were evaluated in the study, which may impact the generalization of the results.

\section{Conclusions}

This analysis using the US DOD data adds real-world evidence about the comparative effectiveness and safety of OAC use for stroke prevention in NVAF. Among NVAF patients in the US DOD population, apixaban initiation was associated with significantly lower risks of stroke/SE and major bleeding compared to warfarin. Dabigatran and rivaroxaban initiation were associated with similar risks of stroke/SE and major bleeding compared to warfarin.

\section{Additional file}

Additional file 1: Table S1. Codes for Exclusion Criteria. Table S2. ICD-9-CM Codes for Stroke/SE and Major Bleeding Endpoints. Table S3. $\mathrm{CHA}_{2} \mathrm{DS}_{2}$-VASc Score Points and Description. Table 4. HAS-BLED Score. (DOCX $26 \mathrm{~kb})$

\section{Abbreviations}

AF: Atrial fibrillation; ARB: Angiotensin-receptor blocker; CCl: Charlson comorbidity index; $\mathrm{CHA}_{2} \mathrm{DS}_{2}$ VASC: Congestive heart failure, hypertension, age $\geq 75$ years, diabetes mellitus, prior stroke or transient ischemic attack or thromboembolism, vascular disease, age 65-74 years, gender category; $\mathrm{CHADS}_{2}$ : Congestive heart failure, hypertension, age $\geq 75$ years, diabetes mellitus, prior stroke or transient ischemic attack or thromboembolism; Cl: Confidence interval; CPT: Current procedural terminology; DOAC: Direct Oral anticoagulant; DOD: Department of Defense; FDA: Food and Drug Administration; Gl: Gastrointestinal; HAS-BLED: Hypertension, abnormal renal and liver function, stroke, bleeding, labile INRs (international normalized ratio), elderly, drugs and alcohol; ACE: Angiotensin-converting enzyme inhibitor; HCPCS: Healthcare common procedure coding system; HR: Hazard ratio; ICD-9-CM: International classification of diseases, 9th revision, clinical modification; ICH: Intracranial hemorrhage; INR: International normalized ratio; NDC: National Drug Code; NVAF: Non-valvular atrial fibrillation; OAC: Oral anticoagulant; PSM: Propensity score matching; SD : Standard deviation; SE: Systemic embolism; TIA: Transient ischemic attack; VKA: Vitamin $\mathrm{K}$ antagonist

\section{Acknowledgements}

Chris Haddlesey and Michael Moriarty of STATinMED Research provided editorial support.

\section{Authors' contributions}

KG, JT, AK, QZ, OD, JM, AN, and TS meet the International Committee of Medical Journal Editors (ICMJE) criteria for authorship of this article, take responsibility for the integrity of the work as a whole, and have given their approval for this version to be published. KG, JT, AK, QZ, OD, JM, AN, and TS conceptualized and designed the study. AK and QZ verified, analyzed, and interpreted the data. KG, JT, AK, QZ, OD, JM, AN, and TS wrote the manuscript and/or substantially contributed to critical revision of the intellectual content.

\section{Funding}

Sponsorship for this study and article processing charges were funded by BristolMyers Squibb and Pfizer Inc. Bristol-Myers Squibb and Pfizer Inc. contributed to the design of the study and writing of the manuscript (for collection, analysis, and interpretation of the data, see author contributions). All authors had full access to all of the data in this study and take complete responsibility for the integrity of the data and accuracy of the analysis.

\section{Availability of data and materials}

The datasets generated during and/or analyzed during the current study are not publicly available due to a data licensing agreement with the United States Department of Defense. The raw data on which the analysis was based are available from the US Department of Defense on reasonable request.

\section{Ethics approval and consent to participate}

This retrospective database analysis did not involve the collection, use, or transmittal of individual identifiable data. As such, Institutional Review Board (IRB) approval to conduct this study was not required and considered exempt according to 45CFR46.101(b)(4): Existing Data \& Specimens - No Identifiers. Both the data set itself and the security of the offices where the data are housed meet the requirements of the Health Insurance Portability and Accountability Act (HIPAA) of 1996.

\section{Consent for publication}

Since this retrospective database analysis did not involve the collection, use, or transmittal of individual identifiable data, patient consent was not required.

\section{Competing interests}

Gupta and Nadkarni are employees of Bristol-Myers Squibb Company, with ownership of stocks in Bristol-Myers Squibb Company. Trocio, Dina, 
Mardekian, and Shank are employees of Pfizer Inc., with ownership of stocks in Pfizer Inc. Keshishian and Zhang are employees of STATinMED Research, a paid consultant to Pfizer and Bristol-Myers Squibb in connection with this study and the development of this manuscript.

\section{Author details}

${ }^{1}$ Bristol-Myers Squibb, Lawrenceville, NJ, USA. ${ }^{2}$ Pfizer Inc., New York, NY, USA.

${ }^{3}$ STATinMED Research, $211 \mathrm{~N}$ 4th Ave, Ste 2B, Ann Arbor, Ml 48104, USA.

Received: 7 January 2019 Accepted: 22 May 2019

Published online: 13 June 2019

\section{References}

1. Wolf PA, Abbott RD, Kannel WB. Atrial fibrillation as an independent risk factor for stroke: the Framingham study. Stroke. 1991;22(8):983-8.

2. Colilla S, Crow A, Petkun W, Singer DE, Simon T, Liu X. Estimates of current and future incidence and prevalence of atrial fibrillation in the U.S. adult population. Am J Cardiol. 2013;112(8):1142-7.

3. Go AS, Hylek EM, Phillips KA, Chang Y, Henault LE, Selby JV, et al. Prevalence of diagnosed atrial fibrillation in adults: national implications for rhythm management and stroke prevention: the anticoagulation and risk factors in atrial fibrillation (ATRIA) study. JAMA. 2001;285(18):2370-5.

4. Hart RG, Pearce LA, Aguilar MI. Meta-analysis: antithrombotic therapy to prevent stroke in patients who have nonvalvular atrial fibrillation. Ann Intern Med. 2007;146(12):857-67.

5. January CT, Wann LS, Alpert JS, Calkins H, Cigarroa JE, Cleveland JC Jr, et al. 2014 AHA/ACC/HRS guideline for the management of patients with atrial fibrillation: a report of the American College of Cardiology/American Heart Association task force on practice guidelines and the Heart Rhythm Society. Circulation. 2014;130(23):2071-104.

6. Connolly SJ, Ezekowitz MD, Yusuf S, Eikelboom J, Oldgren J, Parekh A, et al. Dabigatran versus warfarin in patients with atrial fibrillation. N Engl J Med. 2009;361(12):1139-51.

7. Patel MR, Mahaffey KW, Garg J, Pan G, Singer DE, Werner H, et al. Rivaroxaban versus warfarin in nonvalvular atrial fibrillation. N Engl J Med. 2011;365(10):883-91.

8. Granger CB, Alexander JH, McMurray JJ, Lopes RD, Hylek EM, Hanna M, et al. Apixaban versus warfarin in patients with atrial fibrillation. N Engl J Med. 2011:365(11):981-92

9. Giugliano RP, Ruff CT, Braunwald E, Murphy SA, Wiviott SD, Halperin JL, et al. Edoxaban versus warfarin in patients with atrial fibrillation. N Engl J Med. 2013;369(22):2093-104.

10. Ntaios G, Papavasileiou V, Makaritsis K, Vemmos K, Michel P, Lip GYH. Realworld setting comparison of nonvitamin-K antagonist Oral anticoagulants versus vitamin-K antagonists for stroke prevention in atrial fibrillation: a systematic review and meta-analysis. Stroke. 2017:48(9):2494-503.

11. Deitelzweig S, Farmer C, Luo X, Vo L, Li X, Hamilton M, et al. Risk of major bleeding in patients with non-valvular atrial fibrillation treated with oral anticoagulants: a systematic review of real-world observational studies. Curr Med Res Opin. 2017;33(9):1583-94.

12. Jensen PN, Johnson K, Floyd J, Heckber SR, Carnahan R, Dublin S. Identifying atrial fibrillation from electronic medical data: a systematic review. Pharmacoepidemiol Drug Saf. 2012;21(01):141-7.

13. Teutsch C, Huisman MV, Lip GYH, Diener H-C, Dubner SJ, Changsheng M, et al. Persistence with dabigatran therapy for stroke prevention in patients with non-valvular atrial fibrillation: the Gloria-AF registry. Blood. 2016;128:2616.

14. Yao X, Abraham NS, Sangaralingham LR, Fernanda Bellolio M, Mcbane RD, Shah ND, et al. Effectiveness and safety of dabigatran, rivaroxaban, and apixaban versus warfarin in nonvalvular atrial fibrillation. J Am Heart Assoc 2016:5(6):e003725

15. Thigpen JL, Dillon C, Forster KB, Henault L, Quinn EK, Tripodis Y, et al. Validity of international classification of disease codes to identify ischemic stroke and intracranial hemorrhage among individuals with associated diagnosis of atrial fibrillation. Circ Cardiovasc Qual Outcomes. 2015;8(1):8-14.

16. Cunningham A, Stein CM, Chung CP, Daugherty JR, Smalley WE, Ray WA. An automated database case definition for serious bleeding related to oral anticoagulant use. Pharmacoepidemiol Drug Saf. 2011;20(6):560-6.

17. Amin A, Keshishian A, Trocio J, et al. Risk of stroke/systemic embolism, major bleeding and associated costs in non-valvular atrial fibrillation patients who initiated apixaban, dabigatran or rivaroxaban compared with warfarin in the United States Medicare population. Curr Med Res Opin. 2017:33(9):1595-604

18. Lip GYH, Nieuwlaat R, Pisters R, Lane DA, Crijns HJGM. Refining clinical risk stratification for predicting stroke and thromboembolism in atrial fibrillation using a novel risk factor-based approach: the euro heart survey on atrial fibrillation. Chest. 2010;137(2):263-72.

19. Pisters R, Lane DA, Nieuwlaat R, de Vos CB, Crijns HJGM, Lip GYH. A novel userfriendly score (HAS-BLED) to assess 1-year risk of major bleeding in patients with atrial fibrillation: the euro heart survey. Chest. 2010;138(5):1093-100.

20. Berger ML, Mamdani M, Atkins D, Johnson ML. Good research practices for comparative effectiveness research: defining, reporting and interpreting nonrandomized studies of treatment effects using secondary data sources: the ISPOR good research practices for retrospective database analysis task force report--part I. Value Health. 2009;12(8):1044-52.

21. Willke RJ, Mullins CD. "Ten commandments" for conducting comparative effectiveness research using "real-world data". J Manag Care Pharm. 2011; 17(9 Suppl A):S10-5.

22. McCaffrey DF, Griffin BA, Almirall D, Slaughter ME, Ramchand R, Burgette LF. A tutorial on propensity score estimation for multiple treatments using generalized boosted models. Stat Med. 2013;32(19):3388-414.

23. Austin PC. The use of propensity score methods with survival or time-toevent outcomes: reporting measures of effect similar to those used in randomized experiments. Stat Med. 2014;33(7):1242-58.

24. Austin PC. Balance diagnostics for comparing the distribution of baseline covariates between treatment groups in propensity-score matched samples. Stat Med. 2009:28(25):3083-107.

25. Villines TC, Schnee J, Fraeman K, Siu K, Reynolds MW, Collins J, et al. A comparison of the safety and effectiveness of dabigatran and warfarin in non-valvular atrial fibrillation patients in a large healthcare system. Thromb Haemost. 2015;114(6):1290-8

26. Carmo J, Costa FM, Ferreira J, Mendes M. Dabigatran in real-world atrial fibrillation. Thromb Haemost. 2016;115(04):754-63.

27. Bai Y, Deng H, Shantsila A, Lip GY. Rivaroxaban versus dabigatran or warfarin in real-world studies of stroke prevention in atrial fibrillation. Stroke. 2017:48(4):970-6.

28. Tamayo S, Peacock WF, Patel M. Characterizing major bleeding in patients with nonvalvular atrial fibrillation: a pharmacovigilance study of 27467 patients taking rivaroxaban. Clin Cardiol. 2015;38(2):63-8.

29. Li XY, Deitelzweig S, Keshishian A, Hamilton MJ, Horblyuk R, Gupta K, et al, Effectiveness and safety of apixaban versus warfarin in non-valvular atrial fibrillation patients in "real-world" clinical practice. A propensity-matched analysis of 76,940 patients. Thromb Haemost. 2017;117(6):1072-82.

30. Bai Y, Shi XB, Ma CS, Lip GY. Meta-analysis of effectiveness and safety of oral anticoagulants in atrial fibrillation with focus on apixaban. Am J Cardiol. 2017;120(9):1689-95

\section{Publisher's Note}

Springer Nature remains neutral with regard to jurisdictional claims in published maps and institutional affiliations.

Ready to submit your research? Choose BMC and benefit from:

- fast, convenient online submission

- thorough peer review by experienced researchers in your field

- rapid publication on acceptance

- support for research data, including large and complex data types

- gold Open Access which fosters wider collaboration and increased citations

- maximum visibility for your research: over $100 \mathrm{M}$ website views per year

At BMC, research is always in progress.

Learn more biomedcentral.com/submission 